\title{
More funds urged for contraceptive research
}

London. The United Nations Population Fund (UNFPA) is calling for more effort and money to be spent on research into new methods of contraception as an essential part of stabilizing global population growth.

In its latest State of World Population report, published this week, the UNFPA highlights in particular the need for the development of more effective methods of male contraception, and of female methods that offer protection against both pregnancy and sexually transmitted diseases (STDs), as two of its most urgent tasks.

Other needs listed in the report included recognizing the position of reproductive health care and family planning services as essential parts of primary health care.

The UNFPA proposes that 20 per cent of national resources and international aid should be earmarked for human development, estimating that funding "will have to be raised considerably" to a minimum of US $\$ 17$ billion in 2000 .

The report has been produced in advance of the fifth International Conference on Population and Development (ICPD), to be held in Cairo, Egypt, on 5-13 September.

It points out that last year, according to figures produced by the US Program for Appropriate Technology in Health (PATH), only around three per cent of the total value of global contraceptive sales was spent on contraceptive research and development, in contrast to the 16-19 per cent of revenue spent by pharmaceutical companies.

PATH, which is based in Seattle, Washington D. C., has pointed out that scientists are currently working on more than 50 potential new contraceptive products. But a lack of financial investment means that most of these are merely variations on existing methods of contraception.

UNFPA's proposals coincide with recommendations made at the International Symposium on Contraceptive Research and Development for the year 2000 and Beyond, held in Mexico City in March 1993. They stress in particular that special emphasis in contraceptive development needs to be placed on "women's perceived needs and priorities"; these include methods that are under the user's control and that will protect

\section{‘Population lab' urged for studies}

London. A leading British surgeon is urging the United Nations to set up a "population control laboratory" to bring together scientific experts to tackle the problem of population growth. The proposal is made by Sir Roy Calne, professor of surgery at the University of Cambridge, and one of the world's leading transplant pioneers, in a book to be published next week.

Figures announced last week by the World Bank predict that the global popula tion will increase from 5.6 billion now to around 8.5 billion in 2030 , with almost 90 per cent of the increase in develop ing countries. Calne claims that population contro is now "the most urgent task" facing the United Nations.

Calne argues in his book, Too Many People, that advances in science and technol-

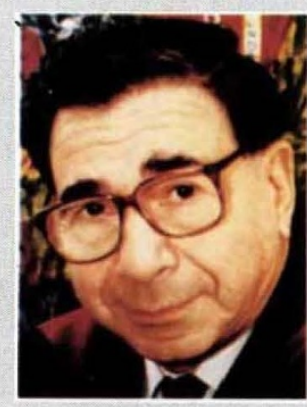

Calne: 'science must give answers'. ogy are partly to blame. "If our species had not developed science, we would have muddled along," he says, pointing to trends such as rising global life expectancy, falling infant mortality, advances in tackling disease and other benefits of science and technology.

But science must now play a role in controlling reproductive rates, says Calne, who wants a non-political, non-religious centre supported by the UN. He suggests that one step in this direction would be to establish a population control laboratory, run on a "non-hierarchical model" under the auspices of the UN.

Calne proposes that such a centre be located somewhere such as New Delhi in India where the problems of population growth are most in evidence. He claims that the idea already has latent support among scientists, pointing out that two years ago, for example, the Union of Concerned Scientists published a document on the problems of population growth, Warning to $\mathrm{Hu}$ manity, signed by 1,600 scientists.

The suggestion has received a mixed reception among the scientific community. Robert May, for example, Royal Society research professor in the department of zoology at the University of Oxford, says he thinks it is an "excellent idea"; but, he goes on to add, given the reality of international organizations, "I don't hold out much hope for it"

Anne McLaren, foreign secretary of the Royal Society, points out that the World Health Organization already runs research programmes in the countries where there is the greatest need, which is "much better than the thought of some great centre that's going to try to impose solutions". Calne appears unfazed by such criticism. "It seems to me the problem is like a runaway cart and we must use scientific methods to pull on the reins," he says.

M. v. against STDs, and safe male methods.

These sentiments are echoed in the draft Programme of Action which participants hope will be agreed upon by member states of the United Nations at next month's conference in Cairo.

The draft calls for "a significant increase" in support from governments and industry to bring potential new methods into use. Areas singled out for attention are male and female barrier methods that both prevent pregnancy and protect against STDs, including HIV/AIDS.

But the chapter of the draft covering sexual and reproductive health research remains riddled, like the rest of the document, with square parentheses around such key phrases as 'fertility regulation' and 'sexual and reproductive health', indicating continuing opposition from the Vatican to attempts to make its scope as broad as possible. The words and phrases were placed in brackets after a failure to reach consensus on meanings or definition during the drawing up of the draft document at the third preparatory committee in New York in April 1994.

The Vatican is opposed to any suggestion that appears to support abortion and its attempts to water down the terms may overshadow much of the other work of the conference. Several participating countries including the Philippines, Argentina, Chile, Iran - have already pledged their support to the Vatican.

Supporters of the programme prefer to stress the recent shifts in emphasis in population policies away from the consideration of population numbers in isolation towards population-related topics embedded in broader development policies.

Decisions in Cairo will be made on a simple majority vote, with more than 140 countries eligible to vote. But supporters of the draft fear that the necessary majority may only be possible with a 'watered down' final declaration. "I would be very disappointed and sad if that was so, and I confidently hope that common sense will prevail," says Anne McLaren, foreign secretary of the Royal Society, which was one of the main organizers of an international 'science summit' of academies held in New Delhi last year. The meeting resulted in a statement to achieve zero population growth (see Nature 366, 3; 1993).

The Inter-Academies Panel on Population Development, set up after the summit, will be represented in Cairo by Prakash Tandon, former president of the Indian $\mathrm{Na}$ tional Science Academy. Tandon will present to the conference the statement agreed in New Delhi, which spoke of the need for an "integrated policy on population and sustainable development". McLaren describes the statement as "very forthright".

Maggie Verral 